Gupta, R, Gregg, M, Du, H and Williams, K

Evaluative application of UKCP09-based downscaled future weather years to simulate overheating risk in typical English homes

Gupta, R, Gregg, M, Du, H and Williams, K (2013) Evaluative application of UKCP09-based downscaled future weather years to simulate overheating risk in typical English homes. Structural Survey, 31 (4). pp. 231-252.

doi: 10.1108/SS-01-2013-0005

This version is available: https://radar.brookes.ac.uk/radar/items/a2979801-1407-4c08-b39c-40510b04e2b3/1/

Available on RADAR: May 2016

Copyright (C) and Moral Rights are retained by the author(s) and/ or other copyright owners. A copy can be downloaded for personal non-commercial research or study, without prior permission or charge. This item cannot be reproduced or quoted extensively from without first obtaining permission in writing from the copyright holder(s). The content must not be changed in any way or sold commercially in any format or medium without the formal permission of the copyright holders.

This document is the post print version of the journal article. Some differences between the published version and this version may remain and you are advised to consult the published version if you wish to cite from it. 


\section{Evaluative application of UKCP09-based downscaled future weather years to simulate overheating risk in typical English}

homes

\section{Author Details}

Author 1 Name: Rajat Gupta

Department: Low Carbon Building Group, Oxford Institute for Sustainable Development, School of Architecture

University/Institution: Oxford Brookes University

Town/City: Oxford

Country: UK

Author 2 Name: Matthew Gregg

Department: Low Carbon Building Group, Oxford Institute for Sustainable Development, School of Architecture University/Institution: Oxford Brookes University

Town/City: Oxford

Country: UK

Author 3 Name: Hu Du

Department: Low Carbon Building Group, Oxford Institute for Sustainable Development, School of Architecture University/Institution: Oxford Brookes University

Town/City: Oxford

Country: UK

Author 4 Name: Katie Williams

Department: Centre for Sustainable Planning and Environments, Department of Planning and Architecture University/Institution: University of the West of England

Town/City: Bristol

Country: UK

Corresponding author: Rajat Gupta

Corresponding Author's Email: rgupta@brookes.ac.uk

\section{Acknowledgments}

The authors gratefully acknowledge the support of the Engineering and Physical Science Research Council (EPSRC) for financially supporting the SNACC project, under Grant reference: EP/G060959/1. The authors would also like to acknowledge the work done by both ARUP and PROMETHUS in generating the FWY and to thank both groups for the provision of these datasets for the SNACC project.

\section{Biographical Details}

Professor Rajat Gupta is Professor of Sustainable Architecture and Climate Change, Director of the Oxford Institute for Sustainable Development (OISD) and leader of the OISD: Low Carbon Building Group at Oxford Brookes University. He is recipient of the inaugural 2006 RIBA President's award for outstanding research related to DECoRuM carbon counting model for neighbourhoods and communities. Professor Gupta is engaged in teaching, research and knowledge exchange activities focussing on carbon counting and global common carbon metrics, building performance evaluation, post occupancy feedback, low carbon communities and climate change adaptation of buildings. As Principal Investigator, he has won close to $£ 4.5$ million in research grants from ESRC, EPSRC, UK Government, World Bank, UNEP, UNFCCC, RIBA, RICS and British Council. He is a Visiting Fellow in Arizona State University, USA, and Faculty Associate in the Smith School of Enterprise and Environment, University of Oxford.

Matt Gregg is a Research Associate in Architecture and Climate Change, based in the Low Carbon Building Group (LCBG) of Oxford Institute for Sustainable Development at Oxford Brookes University. Matt is currently 
involved in a number of climate change adaptation projects including the 3-year EPSRC-funded Suburban Neighbourhood Adaptation for a Changing Climate (SNACC) and five TSB funded Design for Future Climate projects. In 2009, Matt graduated with a MSc Sustainable Building: Performance and Design from Oxford Brookes University. Prior to joining Oxford Brookes in 2010, Matt worked over three years in an architecture practice in Tennessee after getting his BArch degree at the University of Tennessee.

Dr Hu Du is a Lecturer in Architecture and Energy Simulation at the School of Architecture and researcher based in the Low Carbon Building Group of Oxford Institute for Sustainable Development (OISD) at Oxford Brookes University. He is working on a range of cutting-edge research projects on climate change adaptation of buildings and sub-urban neighbourhoods. Currently Dr Du is developing climate change adaptation strategies for five live architecture projects (one eco-town, two schools and two hospitals) funded under the Technology Strategy Board's 'Design for future climate: adapting buildings' programme. He is also developing and monitoring refurbishment strategies for a listed office building funded under the TSB's 'Invest in Innovative Refurb' programme.

Professor Williams is an urban theorist, planner and urban designer. She is Director of the Centre for Sustainable Planning and Environments (SPE). Professor Williams specialises in sustainable urban environments and is known for her work on sustainable neighbourhood design (in relation to sustainable behaviours and climate change adaptation), urban form (compact cities) and land reuse. She has undertaken evidence-based critiques of many key urban policies such as sustainable communities and the urban renaissance. Professor Williams has over $£ 4$ million in research grants from UK research councils, government agencies and industry, and has undertaken consultancy work for central and local governments, and regional and national development agencies. She is currently undertaking EPSRC-funded research on adapting UK suburbs for climate change as part of the 'Living with Environmental Change' Programme, and running an EPSRC-funded programme to support interdisciplinary research in health, environment and technology at UWE.

\section{Structured Abstract:}

Purpose: To critically compare three future weather year (FWY) downscaling approaches, based on the 2009 UK Climate Projections, used for climate change impact and adaptation analysis in building simulation software.

Design/methodology/approach: The validity of these FWYs is assessed through dynamic building simulation modelling to project future overheating risk in typical English homes in 2050s and 2080s.

Findings: The modelling results show that the variation in overheating projections is far too significant to consider the tested FWY datasets equally suitable for the task.

Research and practical implications: It is recommended that future research should consider harmonisation of the downscaling approaches so as to generate a unified dataset of FWYs to be used for a given location and climate projection.

If FWY are to be used in practice, live projects will need viable and reliable FWY on which to base their adaptation decisions. The difference between the datasets tested could potentially lead to different adaptation priorities specifically with regard to time series and adaptation phasing through the life of a building.

Originality/value: The article investigates the different results derived from future weather year application to building simulation. The outcome and implications are important considerations for research and practice involved in future weather year data use in building simulation intended for climate change adaptation modelling.

\section{Keywords:}

UKCP09, time series adjustment, domestic overheating, future weather year data, Design Summer Year, Weather Generator

\section{Article Classification:}

Research paper 
Evaluative application of UKCP09-based downscaled future weather years to simulate overheating risk in typical English homes

\section{Introduction}

Given the documented longevity of buildings and the projected change in climate, existing weather years for building performance simulation, traditionally based on historic climate data, is insufficient for modelling the impact of future change and preparing the building industry for appropriate design, resilience and adaptation for the projected change (Gething 2010, Mylona 2012). Hence, future weather data are being used intensively in building simulation research in the UK to test the potential for overheating and energy use change for buildings in the future (Belcher et al. 2005, CIBSE 2009, Chow and Levermore 2010, Collins et al. 2010, Jentsch et al. 2008, Du et al. 2010, Du et al. 2011,Watkins et al. 2011, Coley and Kershaw 2010, Eames et al. 2012, de Wilde and Tian 2010, Gupta and Gregg 2013). There is also international recognition for this need. In Canada, Robert and Kummert (2012) show through the application of 'morphed' weather years that net-zero energy buildings designed for the current climate miss the net-zero energy target in the future. In Switzerland, Frank (2005) demonstrates that climate change will reduce the heating energy demand of an office building but ultimately increase the cooling energy demand by a factor significantly higher. Other examples are evident in Australia (Guan 2009), China (Chan 2011, Wan et al. 2011a, Wan et al. 2011b) and the USA (Crawley 2007).

Climate change impact on buildings has been projected previously based on different climate models. The most recent climate model for the UK, the UK Climate Projection 2009 (UKCP09), is the most comprehensive package of climate information for the $21^{\text {st }}$ century to be made available for the entire UK to date. The UKCP09 differs from the previous and international climate change models in two fundamental respects. First, UKCP09 provides monthly projections of climate change data on a $25 \mathrm{~km}$ gridscale over seven 30-year time slices starting on a baseline of 1961-1990 for three carbon emission scenarios and a range or probabilities. Second, an accompanying Weather Generator (WG) is used to spatially downscale the $25 \mathrm{~km}$ data to $5 \mathrm{~km}$ and to temporally downscale the monthly data to daily or hourly data. The WG uses stochastic modelling methods to perform the downscaling. For a specific location, time period, and carbon emission scenario, the raw data generated from the UKCP09 WG are in the form of 
3000 years of hourly data. This is not in a form that is recognisable and directly usable by building simulation practitioners. There is therefore the need for weather data in formats suited for building design, planning and management and for the evaluation of these data in practical case studies - specifically for dynamic thermal simulation of buildings and for the assessment of overheating risks. As a result of this recognized need, several research projects have been funded by the UK Engineering and Physical Sciences Research Council (EPSRC) to examine the use of UKCP09 data and the associated WG tool, in producing weather files appropriate for building simulation.

The process of downscaling, developing the climate change data from the base UKCP09 to building simulation future weather years (FWY), is open to a range of methods. The wealth of methodological output has proven to be useful and informative in research, however for the building simulation practitioner, potential problems could arise. Problems such as, which FWY dataset should be used? - As explained in subsequent sections, there are a number of approaches available for FWY development producing different FWY datasets. The uncertainty issues and variation in results are by no means restricted to FWY datasets but also exist internationally with present day stochastic weather files for building performance simulation. As has been recognised over 10 years ago, methodologies can vary (and impact the accuracy of modelling results) due to gaps in weather station data, depth of consideration for the urban heat island effect, and sensitivity of the method to the weather sequence (Crawley and Huang 1997, Aguiar et al. 1999, Argiriou et al. 1999, Boland and Dik 2001, Janjai and Deeyai 2009). These issues are still of concern and can act to compound the issue of future modelling.

Of notable concern, the UK Technology Strategy Board (TSB) has funded 50 live architecture projects to assess climate change impact and adaptation effectiveness. These projects are actively testing designs and proposing adaptation strategies based on a single chosen method (by the project team and not based on an assessment of all methodologies compared). A second problem is explored in the latter half of the paper; significant differences in overheating results and energy use patterns can arise when multiple FWY datasets, developed through different methods, are aligned along their common projection variables (i.e. climate period, emissions scenarios and level of probability) and compared through simulation. The FWY datasets are ultimately analysed through a dynamic building simulation model as this is the platform for which they are developed. Though this paper specifically assesses climate change data in the 
UK, these methods are applicable and even currently used internationally (Robert and Kummert, 2012). These issues and questions are expected to inevitably arise anywhere climate change simulation for buildings are being performed and the solutions found in the UK will be informative for future international work in this field.

\section{Review of future Design Summer Year methodologies}

With the introduction of the UKCP09 probabilistic climate change projections, the EPSRC funded four research projects in 2008 under the use of probabilistic information in building design programme to develop weather files for building performance simulation and to examine the use of the UKCP09 data for building design or assessment. To do so, the research projects needed to first downscale the monthly data into a usable format and though all projects used the UKCP09 WG to downscale the data, different and sometimes multiple methodologies were ultimately developed and tested (Mylona 2012). Three of the four projects are described in the following subsections (Sections 2.4-2.7). The fourth, Low-carbon climate change future (LCF) did not develop single year weather files but instead, Patidar et al. (2011) and Jenkins et al. (2011) used multi-year weather files (e.g. a random selection of 100 years from 3000 years) for building simulation and developed a regression method to calculate interior temperatures based on simulation results.

The SNACC (Suburban neighbourhood adaptation for a changing climate) project, funded under the EPSRC's Adaptation and Resilience to a Changing Climate programme, focuses on adaptation of the built environment through changes to individual homes and entire neighbourhoods, using a socio-technical approach (Gupta and Gregg 2011). This paper is developed out of building simulation testing undertaken as part of the SNACC project. Table 1 summarises a range of future weather year datasets for building simulation including those used for SNACC. The datasets and their methodological approaches are outlined in Sections 2.1-2.7, The highlighted datasets are the datasets which are the subject of testing following the review.

Table 1

\subsection{CIBSE future DSYS}

In the UK the Chartered Institution of Building Services Engineers (CIBSE) provides the Test Reference Year (TRY) and the Design Summer Year (DSY) used by a majority 
of building performance simulators in the UK. CIBSE produced DSY data to enable designers to simulate building performance during a year with a hot, but not extreme, summer. The DSY consists of an actual 1-year sequence of hourly data, selected from the 21-year recorded data sets (typically 1983-2004) to represent a year with the third hottest summer (CIBSE 2002). The selection is based on average dry bulb temperatures during the period April-September. Practitioners predominantly use DSYs to calculate the risk of overheating in a building in terms of percentage of occupied hours (CIBSE 2006).

When the UK Climate Impacts Programme 2002 (UKCIP02 - the predecessor to the UKCP09) climate change data became public, CIBSE and others used the time series adjustment (also called 'morphing') method with the data to generate future DSYs (Jentsch et al. 2008, Belcher et al. 2005). Briefly, the morphing method is to stretch and shift observed weather data to produce a future time series that corresponds to future projections of average changes in the climate model. In the end the two time series are proportionally consistent. Morphing is documented as conceptually straightforward and transparent. The 'ready-made' datasets offered by CIBSE (2008) then became 'standard' data for the industry, thereby providing a common platform for climate change impact assessments. CIBSE offers DSYs for current, 2020s, 2050s and 2080s timelines. For each future timeline, weather data based on four carbon emission scenarios (low, medium low, medium high and high) were made available.

\subsection{ARUP morph DSYS}

A research partner on the SNACC project, ARUP (2011) has provided to the SNACC team two methodologically alternative sets of future weather data based on the UKCP09 climate change projections. They are UKCP09 Morphed data (Morph, in short) and UKCP09 Weather Generator-ARUP data (WG-A, in short). For the first set of future weather data (Morph), ARUP used the method explained in CIBSE TM48 (CIBSE 2009). The variables that have been used to generate the FWYs are dry bulb temperature, wet bulb temperature, wind direction, wind speed and cloud cover. The mean monthly projections of changes to these climate variables were captured from the UKCP09, and they were used to 'morph' current time series weather data. The morphing involved 'stretching' (i.e. scaling) and 'shifting' (i.e. time-adjusting) the current climate values of variables so that they have the same monthly average statistics as the projected climate change variables. 


\subsection{ARUP Weather Generator DSYs - Method F}

The second set of future weather data (WG-A) is also based on UKCP09 projections. Instead of using the morphing method, ARUP used the UKCP09 WG to generate 100 sets of 30 years of hourly data for each time slice, carbon emission scenario and location. The 100 sets of 30 years were then ranked by the mean dry bulb temperature for each set. From this ranked series, the 30 -years at $10^{\text {th }}, 50^{\text {th }}$ and $90^{\text {th }}$ percentile ${ }^{1}$ were selected. For the 30 years data at $10^{\text {th }}$ percentile, the 30 years were ranked from coolest to hottest according to the mean temperature of April-September; the middle of the upper quartile was then specified as the DSY at $10^{\text {th }}$ percentile. This process was repeated for 30 years at $50^{\text {th }}$ percentile and $90^{\text {th }}$ percentile. In order to run the WG for the first time, a random seed must be supplied by the user or the WG itself. This is the number used as the starting point in a random number generation algorithm. The random sampling method in the WG gives the whole range of percentiles in its outputs.

\subsection{COPSE Manchester DRYs - Method A}

As part of the COPSE (Co-incident probabilistic climate change weather data for a sustainable environment) project, Watkins et al. (2012) at Manchester University developed a method of generating future Design Reference Years (DRYs) from UKCP09 climate change projections. In the selection procedure applied, each calendar month of the DRY is derived separately from any other calendar month. For example, 3000 Januaries captured from the UKCP09 WG output and the mean temperatures (or solar, or RH) for each calendar month of the 3000 months are calculated, and the 3000 Januaries are ranked by these monthly means. A 20 -month band is taken centred at a certain percentile (e.g. $87.5 \%$ or $97.5 \%$ in their study) of 3000 months. Then a 'design reference' January is chosen (via the FS-stat method ${ }^{2}$ ) taking into account all three

${ }^{1}$ Common probability percentages associated with the data in the UKCP09 are 10\%: very unlikely to be less than, $50 \%$ : as likely to be less than as it is to be greater than or the central estimate and $90 \%$ : very unlikely to be greater than.

2 The FS-stat (Finkelstein-Schafer statistic) method selects the 'best' calendar month from multi-year data. For each primary parameter (dry-bulb temperature or solar radiation or humidity), the FS-stat method sums the absolute difference between the cumulative distribution of the daily value in an individual month (e.g. a January) and the cumulative distribution of the daily value in all of that calendar month (e.g. 20 Januaries). The months with the smallest FS 
parameters (temperature, solar radiation, relative humidity) and then wind regardless of which primary selection parameter has been used. This month then becomes one of the 12 contributing months to the DRY. The process is repeated for the other 11 months.

The whole process is then repeated for the other primary selection parameters. The temperature-selected DRY and solar-selected DRY would usually be required, with the worst case result being used. If solar gain were known not to be an issue (minimal or no glazing), the temperature-selected DRY alone could be used.

Manchester University offers three sets of DRYs (temperature, solar radiation and relative humidity) for the control, 2020s, 2050s and 2080s timelines. For each timeline and percentile $(87.5 \%$ or $97.5 \%)$, weather data based on low and high carbon emission scenarios were made available.

\subsection{COPSE Northumbria DRYs - Method B}

Also as part of the COPSE project, Du et al. (2012a) at Northumbria University developed another method of generating future DRYs from UKCP09 climate change projections. This method selects three near-extreme summer months and three nearextreme winter months and weaves them into the COPSE Northumbria TRY (Du et al. 2012b). Three near-extreme winter months and three near-extreme summer months were derived separately. For example, 3000 Junes are captured from the UKCP09 WG output and then are ranked by their monthly mean temperatures. A 30-month band is taken centred at a certain percentile (e.g. $85 \%, 99 \%$ in their study) of 3000 months. Then a 'design reference' June is chosen (via the FS-stat method) (ISO 2005) taking into account temperature, solar radiation, relative humidity and wind speed (wind speed as secondary selection criteria). This month then becomes one of the summer contributing months to the DRY. The process is repeated for July and August months. For winter months (December, January and February), the 30-month band is taken at certain percentiles (15\% and $1 \%)$.

statistic are chosen as the most 'average' ('typical' or 'best'). Hence the months chosen using the FS statistic can be considered representative of all the years. This process is followed for each month of the year for each parameter in turn. More details can be found in ISO 15927-4 Standard. 
Northumbria University offers DRYs for the control, 2030s, 2050s and 2080s timelines. For each timeline and percentile $(85 \%$ or $99 \%)$, weather data were made available for low, medium and high emissions scenarios.

The COPSE stakeholder advisory group suggests using a single TRY and DRY, as it is less time and cost consuming for industry application. To balance this with the probabilistic nature of the future climate data, Watkins et al. (2012) and Du et al. (2012a) both provide DRYs at two percentiles $(87.5 \%$ and $97.5 \%$ in COPSE Manchester data, $85 \%$ and $99 \%$ in COPSE Northumbria data).

\subsection{PROMETHEUS DSYS - Method E}

As the outcome of the PROMETHEUS (The use of probabilistic climate change data to future-proof design decisions in the building sector) project, Eames et al. (2011) at Exeter University developed a method for generating probabilistic DSYs from the UKCP09 climate change projections. In the selection procedure applied by Eames et al., for a specific location, climate period and emissions scenario, 100 samples of 30-year data were generated by the UKCP09 WG. For each sample of 30-year data, the year with the fourth warmest April to September was selected as a DSY; therefore there are 100 DSYs available. For each calendar month of these 100 DSYs, the 100 months were then ranked based on the ascending order of the mean monthly temperatures. Then different calendar months at the same percentile (e.g. $10^{\text {th }}, 33^{\text {rd }}, 50^{\text {th }}, 66^{\text {th }}$ and $90^{\text {th }}$ ) were joined together to form the PROMETHEUS probabilistic DSYs. For example, the 10th percentile January month was joined to the 10th percentile February month et cetera.

The PROMETHEUS project offers five DSYs (at $10^{\text {th }}, 33^{\text {rd }}, 50^{\text {th }}, 66^{\text {th }}$ and $90^{\text {th }}$ percentiles respectively) for the control, 2030s, 2050s and 2080s timelines. For each timeline and percentile, weather data based on the medium and high emissions scenarios were made available. The five DSYs (at five different probabilities) offer a wider range of uncertainty compared with COPSE data. In this paper, PROMETHEUS data is named $W G-P$ (Weather Generator- PROMETHEUS) in short.

\subsection{PROCLIMATION DSYs-Methods C,D, G and H}

As the outcome of the PROCLIMATION (The use of probabilistic climate scenarios in building environmental performance simulation) project, Smith and Hanby (2012) examined four methods of generating DSYs from UKCP09 WG output. All four methods retain the concept of using complete years (a complete year selected from 
multi-year data, e.g. 1999 from 1983-2004). This differs from methods proposed by the COPSE project and the PROMETHEUS project. The COPSE DRY was composed of individual calendar months selected from different years (e.g. January from 1981, February from 1990, March from 1984 and so on). The PROMETHEUS DSY retains the concept of using a complete year in the first step of their method, then composing DSYs by individual calendar months in the following step.

The other difference between the PROCLIMATION project and others is that PROCLIMATION used the percentile sampling feature of the UKCP09 WG for two of their methods $(\mathrm{G}$ and $\mathrm{H})$. The percentile sampling means that the probabilistic attribute (percentile) has been embedded in the WG output. ARUP, COPSE and PROMETHEUS used the random sampling feature of the WG. The random sampling output from the WG represents the whole range of probability.

Figure 1 illustrates all methods based on the UKCP09 WG. Method A was used by COPSE Manchester team and Method B was used by COPSE Northumbria team. Method E was used by the PROMETHEUS team. Method F was used by ARUP (WGA) for the SNACC project. Methods C, D, G, and H are the methods examined by the PROCLIMATION team. Among the four methods examined by the PROCLIMATION team using weighted cooling degree hours, Method D has the most flexibility and economy of effort and it provides comparable outputs in relation to the existing morphed methods, if its central estimates are used (Smith and Hanby 2012).

Figure 1

Mylona (2012) reviewed some of the above methods theoretically and points out that the morphing methodology is the preferred method for keeping the consistency between the currently available historic and future weather files. However, Eames et al. (2012) suggests that there are clear issues with the morphing procedure using UKCP09 and caution must be used when investigation the effects of extreme temperature.

\section{Method}

This paper examines three datasets, provided for simulation in the SNACC project, developed by PROMETHEUS and ARUP (table 1) using morphing and statistical modelling. Two tests were conducted. First, a direct comparison was made among three 
weather datasets. Second, building simulations of four types of typical English homes were conducted to calculate future overheating hours. The simulation testing is considered important because this is the platform for which the future weather years were developed.

\subsection{Climate change scenarios}

The following climate change projections were selected:

- two climate periods: 2050s 'medium term' and 2080s 'long term'

- $\quad$ one emissions scenario: medium emissions

- two probabilities: $50 \%$ (central estimate) and 90\% (very unlikely to be greater than)

Additional tests were performed for the 2030s climate period for both medium and high emissions. The authors consider the medium and long term climate periods to sufficiently represent the latter database of future climate change without overlap (figure 2). These latter scenarios are preferred due to the historic and expected longevity of homes in England.

Figure 2

Partially due to limited availability of data, comparisons between all future weather datasets are limited to the medium emissions scenarios, 50\% probability and $90 \%$ probability. These scenarios do however represent climate change scenarios adequate for testing in the SNACC project.

\subsection{Weather data for simulation}

For the SNACC project, three DSY datasets (highlighted in table 1) and corresponding three TRY datasets have been obtained and are being used to test climate change impact and adaptation effectiveness in typical English homes. Of the three datasets to be tested, two varied methodologies, morphing and statistical modelling, for developing FWY are applied and tested in this paper. In addition, statistical modelling is represented by two individually developed datasets. The datasets are:

- $\quad$ UKCP09 Morphed data developed by ARUP (Morph)

- $\quad$ UKCP09 WG data statistically modelled by PROMETHEUS (WG-P)

- $\quad$ UKCP09 WG data statistically modelled by ARUP (WG-A) 
The three datasets are tested for a single location, Stockport, from the list of three cities being studied in the SNACC project (Bristol, Oxford and Stockport). The base file for the Morph dataset is Manchester Ringway Airport's historical CIBSE TRY and DSY. The Manchester Ringway Airport and Stockport are a maximum of $6 \mathrm{~km}$ apart centre to centre. The WG-P and WG-A datasets are both based on the $5 \mathrm{~km}$ grid square over Stockport (Grid number: 3900390). The weather files used for initial comparison are listed in table 2.

For analytical comparison of the three datasets, the average temperature and the average direct solar radiation for the period of April-September are shown in figure 3 and 4 respectively. The temperature difference among the three datasets is very small for 2050 medium 50 percentile weather condition; however, the difference is up to $2.63^{\circ} \mathrm{C}$ for 2080 medium 90 percentile. WG-P appears to always result in higher average temperatures than the others while WG-P shows higher radiation levels in all but the 2050 medium 50 percentile projection. A surprising finding is that the average temperature of WG-A for 2080 medium 90 percentile is less than its 2050 medium 90 percentile's average temperature. In addition, the WG-A average solar radiation is higher in the 2050 s climate period than the 2080 s.

Table 2

Figure 3

Figure 4

The total hours equalling or exceeding a certain temperature $\left(25^{\circ} \mathrm{C}-38^{\circ} \mathrm{C}\right)$ during the April - September period for the different datasets are illustrated in figure 5. Note that there is no clear pattern showing which datasets are always warmer than others. The 50 percentile weather data (two figures at left) tend to give similar results, while the difference among 90 percentile (two figures at right) is significant. As an example, the hours equal to or over $26^{\circ} \mathrm{C}$ at 2080 medium 90 percentile for the three datasets are 170,360 and 600 . 
The hourly temperatures at a random selected week were plotted in figure 6 . As expected, two sets of morphed weather data (red lines) have a strong link given the nature of the morphing method (CIBSE 2009), while the statistical data do not (Jones et al. 2009, Eames et al. 2011). A further investigation is made by applying these weather data to the simulation of four types of English homes. In the interest of comparisons within the datasets the simulation and analysis was expanded to include both DSY and TRY.

Figure 6

\subsection{Simulation tool}

Detailed house level climate change impact and adaptation analysis is being undertaken through building thermal simulation modelling in IES ApacheSim. IES ApacheSim was selected partly due to the wide international usage by both research and practice communities, and partly due to the extensive historical testing and verification (Gough and Rees 2004, IES VE 2010, IES VE 2011). The results from ApacheSim are most likely to reflect the results obtained by building simulation practitioners.

\subsection{Case study buildings}

Case study buildings were used to assess the FWY datasets for two reasons. First, with intense focus on the need for retrofitting homes both at policy level and within the project, there is the interest to test the impact of climate change on existing and representative home typologies in actual locations. Although test cell modelling is an effective way to assess the differences between weather datasets providing a controllable environment over specific climate parameters (Aguiar et al. 1999), the simulation results also depend on whole house thermal dynamics such as occupancy patterns, internal gains, flow of ventilation throughout the house and even the impact (potential shading) of the surrounding environment, data for which is readily available for representative case study houses. This is why Judkoff et al. (2008) question how well single test cell results present the performance of full-scale buildings.

Four home typologies, semi-detached, mid-terraced, detached and purpose built flat, were selected because they represent the four most common home types in England (in the order listed) (DCLG 2010). The constructions are post-1919, theoretically built 
within the period from 1965-1980, which saw the most dwellings built than any other period to date. In addition, the amount of flats built during that period is almost double any other period (DCLG 2010). The most common construction from this period was masonry cavity wall construction. The U-values used in all models are as follows: external walls $=1.4 \mathrm{~W} / \mathrm{m}^{2} \mathrm{~K}$, glazing $($ single $)=4.3 \mathrm{~W} / \mathrm{m}^{2} \mathrm{~K}$, ground floor $=0.75$ $\mathrm{W} / \mathrm{m}^{2} \mathrm{~K}$, roof $=0.35 \mathrm{~W} / \mathrm{m}^{2} \mathrm{~K}$ (Allen and Pinney, 1990). Furthermore, while the homes are occupied, the windows were set to open for natural ventilation whenever the interior temperature exceeds $22^{\circ} \mathrm{C}$. Please refer to Gupta and Gregg (2012) for comprehensive construction, occupancy and operational details of the modelled homes. In contrast to the occupancy details available in the reference above, each home is occupied by a working couple with no dependants. The construction and occupancy are intentionally maintained as controls so that variation between the homes would be attributed only to physical exposure, e.g., building element orientation, number of exposed walls and scale.

Figure 7 shows the homes modelled and used for simulation. All plans and details apart from the flat were obtained from Allen and Pinney (1990). The flat, however, is modelled after the plan of an actual flat in Oxford.

Figure 7

\subsection{Overheating criteria}

The authors chose to select a single, simple variable that is relevant to climate change impact research and particularly an issue in current policy, therefore the FWY datasets are compared based on annual overheating results from each home type (DCLG 2011). Understanding overheating in the homes is an essential first step for the modelling phase of the SNACC research; mitigation of overheating is one of the foundational conditions on which the technical performance of suggested adaptation strategies will be based. Much of this is explored in Gupta and Gregg (2012). The intent of this paper, however, is not to establish the overheating potential in the modelled homes or to suggest adaptation strategies that are effective to mitigate overheating; the method through which the FWY files are assessed is simply through the measurement and comparison of potential overheating simplified as annual hours (and percentage) over a specific temperature for a specific space. Furthermore, it is outside the scope of this paper and beyond purpose to assess the reason for overheating, the impact of climate 
change on winter heating demand, potential cooling energy demand, etc.

The primary bedroom and living room of each home are assessed against the CIBSE definition for overheating. For bedrooms, $1 \%$ of annual occupied hours over the operative temperature of $26^{\circ} \mathrm{C}$ and for living spaces, $1 \%$ of annual occupied hours over the operative temperature of $28^{\circ} \mathrm{C}$ and the DSY should be used to calculate overheating (CIBSE 2006). Though CIBSE (2006) Guide A recommends assessing overheating through the use of DSY files, both TRY and DSY files are used to compare results in this study. Based on the CIBSE definition for overheating, it can be established that there is overheating in the bedrooms of the homes for most scenarios and in some cases far beyond the $1 \%$ of annual occupied hours. It is important to note that natural ventilation, through the occupancy controlled opening of windows, is being utilised in the models to reduce overheating, as it is assumed that this is the most obvious and already utilised adaptation for dwellings.

\section{Results}

\subsection{Comparing FWY using future overheating risk}

The three FWY datasets were simulated for the four home types. The following figures present the actual hours (x-axis) and percentage of occupied hours for overheating, in the bedroom (figure 8) and living room (figure 9) of each home type, for the 2050s and 2080s. The bars in the graphs are stacked to compare the three sources of FWY.

Overall the three datasets tend to be fairly aligned when considering overheating at $50 \%$ probability. When comparing $90 \%$ probability the differences are more noticeable as was the case in figure 5. The Morph dataset, for the most part, tends to be either midrange or lower in overheating hours as compared to the other two datasets. This appears to correspond with both the mean temperature and solar radiation analysis. These findings are not in agreement with the findings in Eames et al. (2011) where a morphed dataset was found to be overestimating change when compared to the output of the WG. Though the morphed dataset in the former reference used UKCIP02 data, the baseline time series remains the same (1983-2004). Another important difference to note is that the former reference used whole house internal temperatures to ascertain their findings. When the Morph overheating does surpass the $W G$ - $A$ dataset in the $2080 \mathrm{~s}$ this actually appears to be a possible underestimation in the $W G-A$ dataset when 
considering the overheating difference between the 2050s and 2080s for $W G-A$. This difference is considered questionable because the UKCP09 outputs for the same location and projections being modelled show a clear upward trend in both mean air temperature change and net surface shortwave flux (NSSWF) (table 3).

Table 3

Figure 8

Figure 9

\subsection{Comparing two varied weather generator outputs}

Two trends are clearly noticeable from figure 8 and 9 with regard to the two WG developed FWY datasets. First, according to the $W G-A$ dataset, the most significant overheating for both the bedroom and living room is found in the 2050s climate period at $90 \%$ probability for the DSY projection. The TRY is almost comparable between the 2050 s and 2080s while still slightly higher in the 2050s. With respect to overheating in both climate periods and probabilities, comparing TRY to TRY and DSY to DSY, the $W G-P$ dataset follows a more predictable pattern where overheating hours decrease as the climate period and respective probabilities descend. Comparing the DSY files to the TRY files in a dataset brings the discussion to the second trend. The $W G-A$ dataset appears to be consistent in a pattern where DSY files result in more overheating than TRY files as expected. The $W G-P$ dataset on the other hand, appears to provide random variation where the DSY file does not always produce more overheating than the TRY file from the same climate projection. As an example, refer to figure 9, for all homes in the 2080 s at $50 \%$ probability, the TRYs in all cases result in more overheating than the DSYs. For the most part, however, when the TRY does show more overheating than the DSY, the difference between the two are quite small. Kershaw et al. (2010) documented a similar issue when testing baseline DSY files against a full base set of weather years on a number of building types. They found that the DSY would regularly underestimate the overheating within a building when compared to the third warmest internal year from the base set. The reason suggested is that the internal temperature of buildings can be affected by a number of variables such as wind speed and cloud cover, whereas the 
DSY is constructed to reflect the third hottest summer for a climate period as measured by external average temperature alone.

Overall the FWY files appear to be producing quite significant differences in the results. Three possible reasons for these differences are as follows: first, flaws may exist in the method of generating datasets; second, the definition of 'percentile' in different methods may not be same, because the 'percentile' selection process happened at different stages (highlighted in redlines in figure 1); third, the uncertainty contained within 3000 future years (for example) is far beyond a situation that would allow a single method of statistical modelling of climate change data to stand as the industry representative of the data. Some variations are greater than others and this difference can clearly be seen in the 2080s time series for all homes. For example, the difference in the overheating for each probability and file type, i.e. DSY and TRY, is roughly half between the $W G-A$ and $W G-P$ FWY datasets. In other words, as an example, strategies taken to reduce or eliminate the overheating (e.g. glazing change or shading of glazing) with the $W G-A$ dataset may not be sufficient or as effective according to the $W G-P$ dataset. This difference can clearly be seen in figures 10 and 11 . These figures display the percentages of overheating hours for the $W G-P$ and $W G-A$ datasets at increasing temperature thresholds using DSY files for the bedroom of the flat, according to two climate periods: 2050s, medium emissions, $90 \%$ probability and $2080 \mathrm{~s}$, medium emissions, $90 \%$ probability.

Figure 10

Figure 11

When viewed this way, it is clear that the two datasets indicate completely different climate periods for the greatest overheating potential, whereas the $W G-A$ dataset is showing the $2050 \mathrm{~s}$ to be the most significant and the WG-P datasets is showing the 2080s to be the most significant. The $W G-A$ dataset is either overestimating the impact for the 2050s or underestimating the impact for the 2080s and conversely the $W G-P$ dataset could be performing similarly. Designing for the 'wrong' dataset could lead to erroneous conclusions, e.g., unnecessary energy use or under-adapted homes. Given this anomaly further investigation was performed using the 2030s and high emissions scenario. 


\subsection{Further testing using the 2030s climate period}

The 2030s climate series for both the $W G-A$ and $W G-P$ datasets were also tested for medium and high emissions scenarios (figure 12). While the number of tests that could potentially be performed is very high considering all possible emissions scenario and probability combinations, these additional tests were run to support and verify findings already presented above. From these tests the most obvious outcome was that the two datasets are again considerably different in overheating projection. Overheating in the $W G-P$ dataset appears to be predictably higher where expected, i.e., high emissions scenario versus medium and $90 \%$ probability versus $50 \%$. Overheating in the $W G-A$ dataset is not providing expected results whereas the medium emissions $90 \%$ DSY is showing the greatest overheating even beyond the high emissions scenario and the high emissions scenario $50 \%$ DSY is showing overheating above the $90 \%$ probabilities for the high emissions scenario.

Figure 12

\section{Discussion}

As building regulations in the UK and internationally should inevitably begin to include adaptation to future climate change as a part of an overarching intent to reduce carbon emissions in the built environment, the industry will need FWY datasets for each specific location which are robust, yet consistent, transparent and valid for testing and effective in results. Figure 13 shows an example of a potential dataset. The box puts a boundary on the extent of data which may define a FWY dataset for every $5 \mathrm{~km}$ square grid of the UK. For every location there is the potential to have 210 FWY files in a dataset, this allows for seven climate periods, three emissions scenarios and a minimum of five probabilities. This is an example of the range of projections that could be available for every location and can of course be expanded to an infinite number of probabilities. Outside the bounding box is the current situation, multiple methodologies creating multiple FWY datasets (five are shown simply for example whereas nine have been reviewed in Section 2).

Figure 13

As has been demonstrated, a number of available FWY datasets, derived using different downscaling approaches for the same location, can differ widely in their 
results. Where does this leave the future of modelling climate change impacts when attempting to project overheating risk and effective adaptation strategies? As the Technology Strategy Board (TSB 2012) is currently funding 50 live projects to be adapted to future climate change, these projects will need viable and reliable FWY on which to base their adaptation decisions. The difference between the datasets tested could potentially lead to different adaptation priorities specifically with regard to time series and adaptation phasing through the life of a building.

Projecting a building's response to future climate change is adequately complicated when considering the wide range of probabilities and emissions scenarios one must work with in order to understand the impact of climate change on a building. To compound this problem, the variation in the statistical translation of the future climate change, as is done through downscaling, has been exhibited to generate wide variation in outcomes. Considering the probabilistic nature of climate change projection, can there be a 'correct' dataset of FWY for a given location? Does this uncertainty in FWY output signify the need for yet another probabilistic category; a probabilistic category that covers the range of outputs demonstrated in this paper (possibly even beyond what is shown here)? An interesting alternative approach is to use multi-year weather data to examine the whole range of uncertainties; however this either requires a fast building simulation engine or a new calculation method. Jenkins et al. (2011) developed a regression formula to calculate interior temperature by using Principal Component Analysis. Du et al. (2012a) also developed a regression formula to calculate room cooling load by using step-wised multiple regression. Regression analysis of a large number of probable variations may be a more robust way to assess probabilistic simulation results.

\section{Conclusion}

Which method is ideal? Although more versatile, statistical modelling clearly shows more uncertainty with outcome between the two WG based datasets. It does not appear that from the definition of statistical modelling that such large variations should exist when comparing datasets formed through the same primary methodology (statistical modelling). There are however significant differences that could possibly lead to the construction of buildings either under-adapted and uncomfortable, in need of costly refurbishment or with over-sized cooling leading to significant energy use, large energy 
bills and preventable $\mathrm{CO}_{2}$ emissions. Alternatively, although the morphing method is limited in scope with regard to location and observed data, the non-dependence on large quantities of data and the transparency of the method appears to allow a replicable dataset to be created every time. Clearly, however, incorrect data can be replicated continually.

This paper is not in the position to demonstrate which FWY dataset or method is 'correct' but to establish that the variation is far too significant to ignore. Furthermore, the limitations within the methodologies do not necessarily create inaccurately downscaled projections. A single 'correct' methodology does not even need to be defined but the results should lead to decisions that are confident with the outcome regardless of methodology used. However, a single dataset for each given location, climate period, emissions scenario and probability level may be necessary for results that can be both consistently replicated and trusted.

Based on a number of reviews of recent research on climate change impacts on the building sector, research is still on-going in many areas and further work will be needed to investigate the application of all above weather years to the same case studies in order to examine their significance in building performance (de Wilde and Coley 2012, Mylona 2012, Street 2012). This need suggests the opportunity for projects involving both the building performance simulator and the future weather year engineers. One such example of planned progress is the CIBSE Climate Task Force, which is exploring potential ways to reflect current and future weather and extreme events for building design (Mylona 2012). In conclusion, it is recommended that future research should consider harmonisation of the various downscaling approaches so as to either ensure that methodologies create FWY that result in an acceptable range of variation or generate a unified dataset of FWY for a given location and climate change projection. The authors are however not assuming that the resolution of these issues will be a simple task.

\section{References}

Aguiar, R., Camelo, S. and Goncalves, H. (1999) "Assessing the value of typical meteorological years built from observed and from synthetic data for building thermal simulation", in Proceedings of the 6th International IBPSA Conference Building Simulation, Kyoto. 
Argiriou, A., Lykoudis, S., Kontoyiannidis, S., Balaras, C.A., Asimakopoulos, D., Petrakis, M. and Kassomenos, P. (1999) 'Comparison of methodologies for TMY generation using 20 years data for Athens, Greece', Solar Energy, Vol. 66, No. 1, pp. 33-45.

Allen, E. A. and Pinney, A. A. (1990), Standard Dwellings for Modelling: Details of Dimensions, Construction and Occupancy Schedules, Building Environmental Performance Analysis Club, Watford.

ARUP (2011), "SNACC Internal Report: Generation of DSY and TRY weather years for the case study locations using the UKCP09 climate change projections. Ove Arup \& Partners Ltd Job number 212178.

Belcher, S., Hacker, J. and Powell, D. (2005), "Constructing design weather data for future climates", Building Service Engineering Research and Technology, Vol. 26 No. 1, pp. 49-61.

Boland, J. and Dik, M. (2001), 'The level of complexity needed for weather data in models of solar system performance', Solar Energy, Vol. 71, No. 3, pp. 187 198.

Chan, A. L. S. (2011), "Developing future hourly weather files for studying the impact of climate change on building energy performance in Hong Kong", Energy and Buildings, Vol. 43 No. 10, pp. 2860-2868.

Chow, D. H. and Levermore, G. J. (2010), "The effects of future climate change on heating and cooling demands in office buildings in the UK", Building Services Engineering Research and Technology, Vol. 31 No. 4, pp. 307-323.

CIBSE (2002), Guide J Weather, solar and illuminance data, Chartered Institution of Building Services Engineers, London.

CIBSE (2006), Environmental Design: CIBSE Guide A, Chartered Institution of Building Services Engineers, London.

CIBSE (2008), "Current and Future CIBSE Weather Data", available at: https://www.cibseknowledgeportal.co.uk/component/dynamicdatabase/?layout= publication\&revision id=31\&st=future+weatheryear (accessed 1 March 2012).

CIBSE (2009), TM48:The use of Climate Change Scenarios for Building Simulation: the CIBSE Future Weather Years, Chartered Institution of Building Services Engineers, London.

Coley, D. and Kershaw, T. (2010), "Changes in internal temperatures within the built environment as a response to a changing climate", Building and Environment, Vol. 45 No.1, pp. 89-93.

Collins, L., Natarajan, S. and Levermore, G. (2010), "Climate change and future energy consumption in UK housing stock", Building Services Engineering Research and Technology, Vol. 31 No. 1, pp. 75-90. 
Crawley, D. B. (2007), "Creating weather files for climate change and urbanization impacts analysis", in Building Simulation 2007, 03-06 September 2007 Beijing, China, pp. 1075-1082.

Crawley, D. B. and Joe Huang, Y. (1997) "Does it matter which weather data you use in energy simulations?", Building Energy Simulation News, Simulation Research Group, Lawrence Berkeley National Laboratory, Vol. 18, No. 1, pp. 212.DCLG (2010),

English Housing Survey: Headline Report 2008-09, Department for Communities and Local Government, London.

de Wilde, P. and Coley, D. (2012), "The implications of a changing climate for buildings", Building and Environment, Vol. 55, pp. 1-7.

de Wilde, P. and Tian, W. (2010), "The role of adaptive thermal comfort in the prediction of the thermal performance of a modern mixed-mode office building in the UK under climate change", Journal of Building Performance Simulation, Vol. 3 No. 2, pp. 87-101.

Du, H., Edge, J. and Underwood, C. (2011), "Modelling the impacts of new UK future weather data on a school building", in Building Simulation 2011, 14-16 November 2011, Sydney, Australia.

Du, H., Underwood, C. and Edge, J. (2010), "Modelling the impact of a warming climate on commercial buildings in the UK", in. Clima 2010 -10th REHVA World Congress "Sustainable Energy Use in Buildings" 9-12 May 2010 Antalya, Turkey.

Du, H., Underwood, C. and Edge, J. (2012a), "Generating design reference years from the UKCP09 projections and their application to future air-conditioning loads", Building Services Engineering Research and Technology, Vol. 33 No. 1, pp. 6379.

Du, H., Underwood, C. P. and Edge, J. S. (2012b), "Generating test reference years from the UKCP09 projections and their application in building energy simulations", Building Services Engineering Research and Technology, Vol. 33 No. 4, pp. 387-406.

Eames, M., Kershaw, T. and Coley, D. (2011), "On the creation of future probabilistic design weather years from UKCP09", Building Services Engineering Research and Technology, Vol. 32 No. 2, pp. 127-142.

Eames, M., Kershaw, T. and Coley, D. (2012), "A comparison of future weather created from morphed observed weather and created by a weather generator", Building and Environment, Vol. 56, pp. 252-264.

Frank, T.H. (2005), "Climate change impacts on building heating and cooling energy demand in Switzerland", Energy and Buildings, Vol. 37 No. 11, pp. 1175-1185.

Gething, B. (2010), "Design for future climate - Opportunities for adaptation in the built environment", available at: 
http://www.innovateuk.org/ourstrategy/innovationplatforms/lowimpactbuilding/ design-for-future-climate-report-.ashx (accessed 4 May 2012).

Gough, M. and Rees, C. (2004), Tests performed on ApacheSim in accordance with ANSI/ASHRAE Standard 140-2001, IES Ltd, Glasgow.

Guan, L. (2009), "Preparation of future weather data to study the impact of climate change on buildings", Building and Environment, Vol. 44 No. 4, pp. 793-800.

Gupta, R. and Gregg, M. (2011), "Adapting UK suburban neighbourhoods and dwellings for a changing climate", Advances in Building Energy Research, Vol. 5 No. 1, pp. 81-108.

Gupta, R. and Gregg, M. (2012), "Using UK climate change projections to adapt existing English homes for a warming climate", Building and Environment, Vol. 55, pp. 20-42.

Gupta, R. and Gregg, M. (2013), "Preventing the overheating of English suburban homes in a warming climate", Building Research and Information, Vol. 41 No. 3, pp. 281-300.

IES VE (2010), "Space-heating equipment performance tests performed on ApacheSim in accordance with ANSI/ASHRAE Standard 140-2007", available at: http://www.iesve.com (accessed $7^{\text {th }}$ July 2012).

IES VE (2011). "Space-cooling equipment performance tests performed on ApacheSim in accordance with ANSI/ASHRAE Standard 140-2007", available at: http://www.iesve.com (accessed $7^{\text {th }}$ July 2012).

ISO (2005), ISO 15927-4: Hourly data for assessing the annual energy use for heating and cooling.

Janjai, S. and Deeyai, P. (2009), " Comparison of methods for generating typical meteorological year using meteorological data from a tropical environment", Applied Energy, Vol. 86, pp. 528-537.

Jenkins, D. P., Patidar, S., Banfill, P.F.G. and Gibson, G.J. (2011), "Probabilistic climate projections with dynamic building simulation: Predicting overheating in dwellings", Energy and Buildings, Vol. 43 No. 7, pp. 1723-1731.

Jentsch, M. F., Bahaj, A. S. and James, P. A. B. (2008), "Climate change future proofing of buildings--Generation and assessment of building simulation weather files", Energy and Buildings, Vol. 40 No. 12, pp. 2148-2168.

Jones, P., Kilsby, C., Harpham, C., Glennis, V. and Burton, A. (2009), "UK Climate Projections science report: Projections of future daily climate for the UK from the Weather Generator", University of Newcastle, UK.

Judkoff, R., Wortman, D., O'Doherty, B. and Burch, J. (2008). A Methodology for Validating Building Energy Analysis Simulations Technical Report NREL/TP550-42059. 
Kershaw, T., Eames, M. and Coley, D. (2010), "Comparison of multi-year and reference year building simulations", Building Services Engineering Research and Technology, Vol. 31 No. 4, pp. 357-369.

Mylona, A. (2012), "The use of UKCP09 to produce weather files for building simulation", Building Services Engineering Research and Technology, Vol. 33 No. 1, pp. 51-62.

Patidar, S., Jenkins, D.P., Gibson, G.J. and Banfill, P.F.G. (2011), "Statistical techniques to emulate dynamic building simulations for overheating analyses in future probabilistic climates", Journal of Building Performance Simulation, Vol. 4 No. 3, pp. 271-284.

Robert, A. and Kummert, M. (2012), "Designing net-zero energy buildings for the future climate, not for the past", Building and Environment, Vol. 55, pp. 150158.

Smith, S. T. and Hanby, V. I. (2012), "Methodologies for the generation of design summer years for building energy simulation using UKCP09 probabilistic climate projections", Building Services Engineering Research and Technology, Vol. 33 No. 1, pp. 9-17.

Street, R. B. (2012), "Guest Editorial", Building Services Engineering Research and Technology, Vol. 33 No. 1, pp. 5-7.

TSB (2012), Design for Future Climate Report, Technology Strategy Board, London.

UK Climate Projections (2011), UK Climate Projections 2009 User Interface, available at: http://ukclimateprojections-ui.defra.gov.uk/ui/admin/login.php (accessed 4th November 2011).

Wan, K. K. W., Li, D. H. W. and Lam, J. C. (2011a), "Assessment of climate change impact on building energy use and mitigation measures in subtropical climates", Energy, Vol. 36 No. 3, pp. 1401-1414.

Wan, K. K. W., Li, D. H. W., Liu, D. and Lam, J. C. (2011b), "Future trends of building heating and cooling loads and energy consumption in different climates", Building and Environment, Vol. 46 No. 1, pp. 223-234.

Watkins, R., Levermore, G. and Parkinson, J. (2011), "Constructing a future weather file for use in building simulation using UKCP09 projections", Building Services Engineering Research and Technology, Vol. 32 No. 3, pp. 293-299.

Watkins, R., Levermore, G. J. and Parkinson, J. B. (2013), "The design reference year a new approach to testing a building in more extreme weather using UKCP09 projections", Building Services Engineering Research and Technology, Vol. 34 No. 2, pp. 165-176. 
Tables

Table 4 Summary of future weather data

\begin{tabular}{|l|l|l|l|l|l|}
\hline Name of weather data & $\begin{array}{c}\text { Climate } \\
\text { projection }\end{array}$ & Method & $\begin{array}{c}\text { Sampling } \\
\text { method in } \\
\text { WG }\end{array}$ & $\begin{array}{c}\text { Complete/ } \\
\text { composited } \\
\text { year }\end{array}$ & $\begin{array}{c}\text { Short } \\
\text { name in } \\
\text { this paper }\end{array}$ \\
\hline CIBSE Future DSY & UKCIP02 & Morphing & $/$ & Complete & $/$ \\
\hline ARUP morphed DSY & UKCP09 & Morphing & Random & Complete & Morph \\
\hline ARUP WG DSY & UKCP09 & Method F & Random & Complete & WG-A \\
\hline COPSE Manchester DRY & UKCP09 & Method A & Random & Composited & $/$ \\
\hline $\begin{array}{l}\text { COPSE Northumbria } \\
\text { DRY }\end{array}$ & UKCP09 & Method B & Random & Composited & $/$ \\
\hline PROMETHEUS DSY & UKCP09 & Method E & Random & Composited & WG-P \\
\hline PROCLIMATION DSY & UKCP09 & Method C & Random & Complete & $/$ \\
\hline PROCLIMATION DSY & UKCP09 & Method D & Random & Complete & $/$ \\
\hline PROCLIMATION DSY & UKCP09 & Method G & Percentile & Complete & $/$ \\
\hline PROCLIMATION DSY & UKCP09 & Method H & Percentile & Complete & $/$ \\
\hline
\end{tabular}

Table 5 Weather files used for comparison

\begin{tabular}{|l|c|c|}
\hline UKCP09 Projection & Source / title & Weather file type \\
\hline \multirow{2}{*}{ 2050 Medium 50\% } & Morph & DSY \\
\cline { 2 - 3 } & WG-A & DSY \\
\cline { 2 - 3 } 2050 Medium 90\% & WG-P & DSY \\
\cline { 2 - 3 } & Morph & DSY \\
\cline { 2 - 3 } & WG-A & DSY \\
\hline \multirow{3}{*}{2080 Medium 50\% } & Morph & DSY \\
\cline { 2 - 3 } & WG-A & DSY \\
\cline { 2 - 3 } & WG-P & DSY \\
\hline \multirow{2}{*}{2080 Medium 90\% } & Morph & DSY \\
\cline { 2 - 3 } & WG-A & DSY \\
\cline { 2 - 3 } & WG-P & DSY \\
\hline
\end{tabular}


Table 6 Climate change projections for the case study location, Stockport, 25km grid cell 1274(UK Climate Projections 2011)

\section{Climate change variable $\quad 2050$ medium emissions $\quad 2080$ medium emissions}

Summer temperature

\begin{tabular}{c|cc|c}
$\mathbf{5 0 \%}$ & $\mathbf{9 0 \%}$ & $\mathbf{5 0 \%}$ & $\mathbf{9 0 \%}$ \\
$+2.4^{\circ} \mathrm{C}$ & $+4.0^{\circ} \mathrm{C}$ & $+3.4^{\circ} \mathrm{C}$ & $+5.6^{\circ} \mathrm{C}$
\end{tabular}

change

Summer NSSWF change $\quad+6.4 \mathrm{~W} / \mathrm{m}^{2} \quad+17.0 \mathrm{~W} / \mathrm{m}^{2} \quad+8.5 \mathrm{~W} / \mathrm{m}^{2}+21.6 \mathrm{~W} / \mathrm{m}^{2}$ 


\section{Figures}

Figure 4 Available methods of generating DSYs

Figure 5 Climate time scale diagram; climate periods cover 30 years of climate data

Figure 6 Apr-Sep average temperatures

Figure 4 Apr-Sep average direct solar radiation (taken between the daily hours of 8:00-20:00)

Figure 5 Total hours equalled or exceeded certain temperature

Figure 6 Hourly temperatures

Figure 7 Image of the plans and perspectives showing orientations and room divisions of the four home types

Figure 8 Hours above $26^{\circ} \mathrm{C}$ and percentage of occupied hours of overheating in the bedroom for each home type

Figure 9 Hours above $28^{\circ} \mathrm{C}$ and percentage of occupied hours of overheating in the living room for each home type

Figure 10 Percentage of overheating hours above a specific temperature for the 2050s, medium emissions scenario at $90 \%$ probability

Figure 11 Percentage of overheating hours above a specific temperature for the 2080s, medium emissions scenario at $90 \%$ probability

Figure 12 Number of occupied hours above $26^{\circ} \mathrm{C}$ in the primary bedroom of the flat for $2030 \mathrm{~s}$ medium and high emissions scenarios

Figure 13 Diagrammatic explanation of FWY datasets. Note: an entire FWY dataset shown (enclosed in the box) is an example of what would be necessary to embody the probabilistic nature of the climate change data and to allow a user access to all climate periods and emissions scenario options. 


\section{Figures}

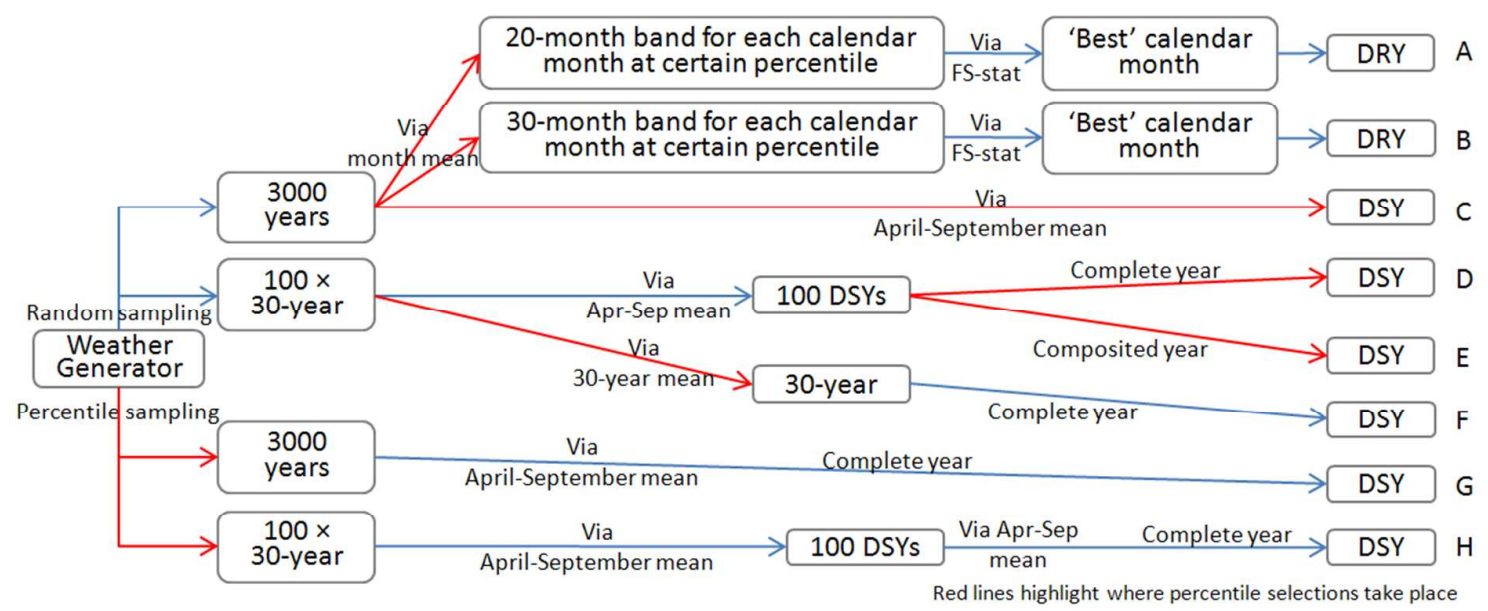

Figure 1 Available methods of generating DSYs 


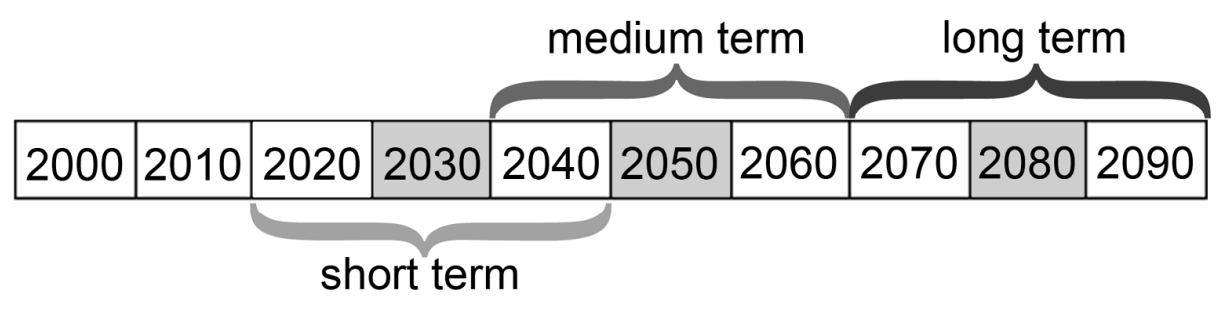

Figure 2 Climate time scale diagram; climate periods cover 30 years of climate data 


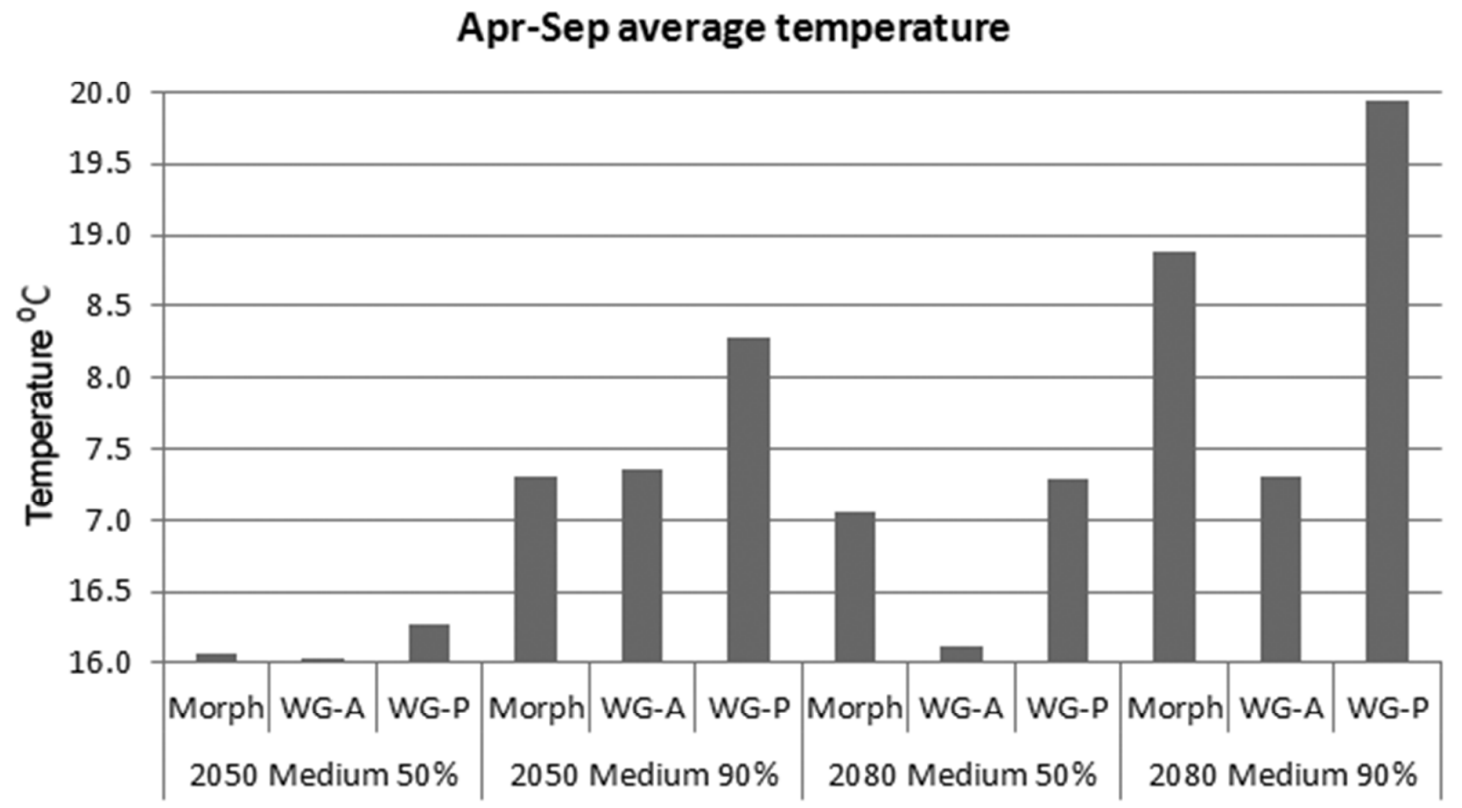

Figure 3 Apr-Sep average temperatures 


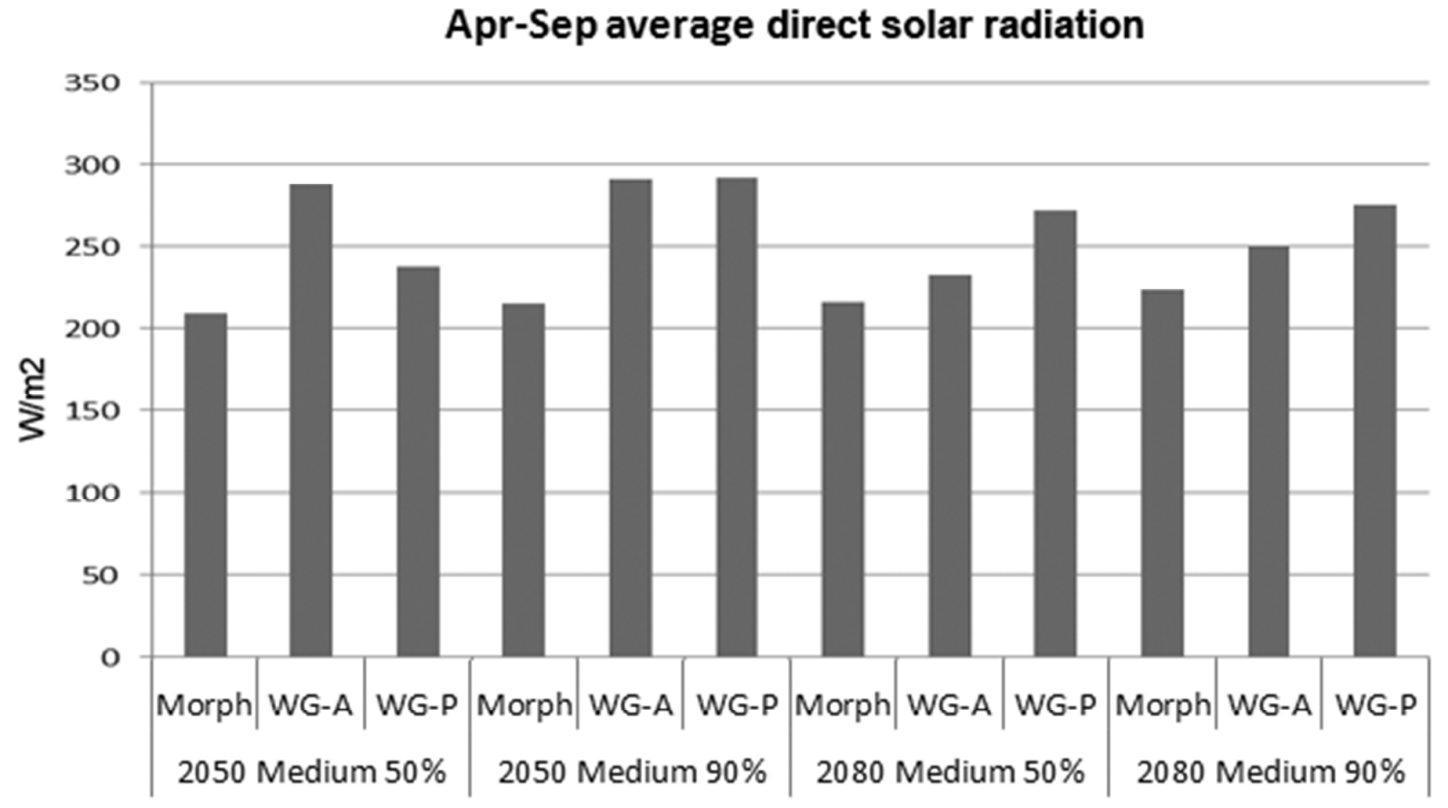

Figure 4 Apr-Sep average direct solar radiation (taken between the daily hours of 8:00-20:00) 

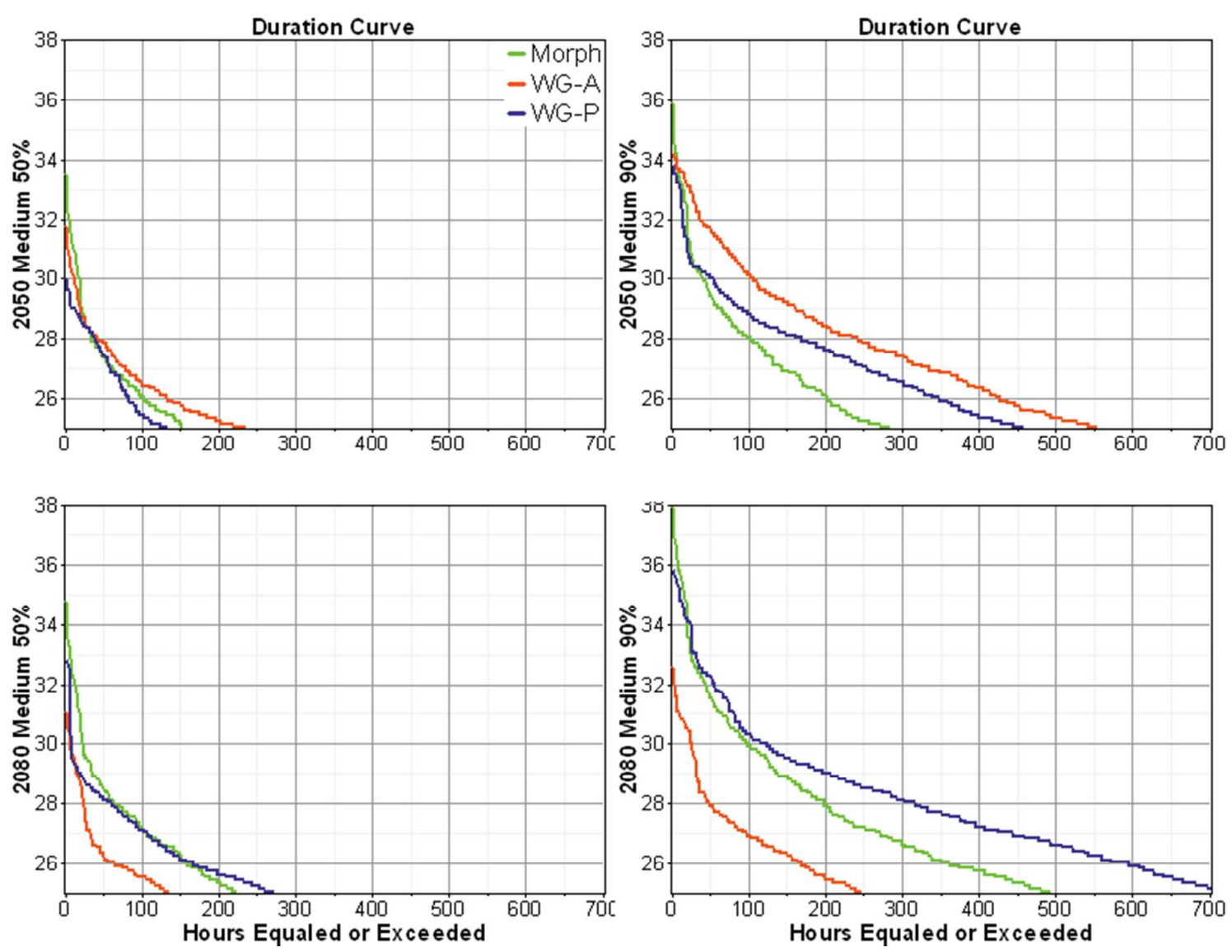

Figure 5 Total hours equalled or exceeded certain temperature 


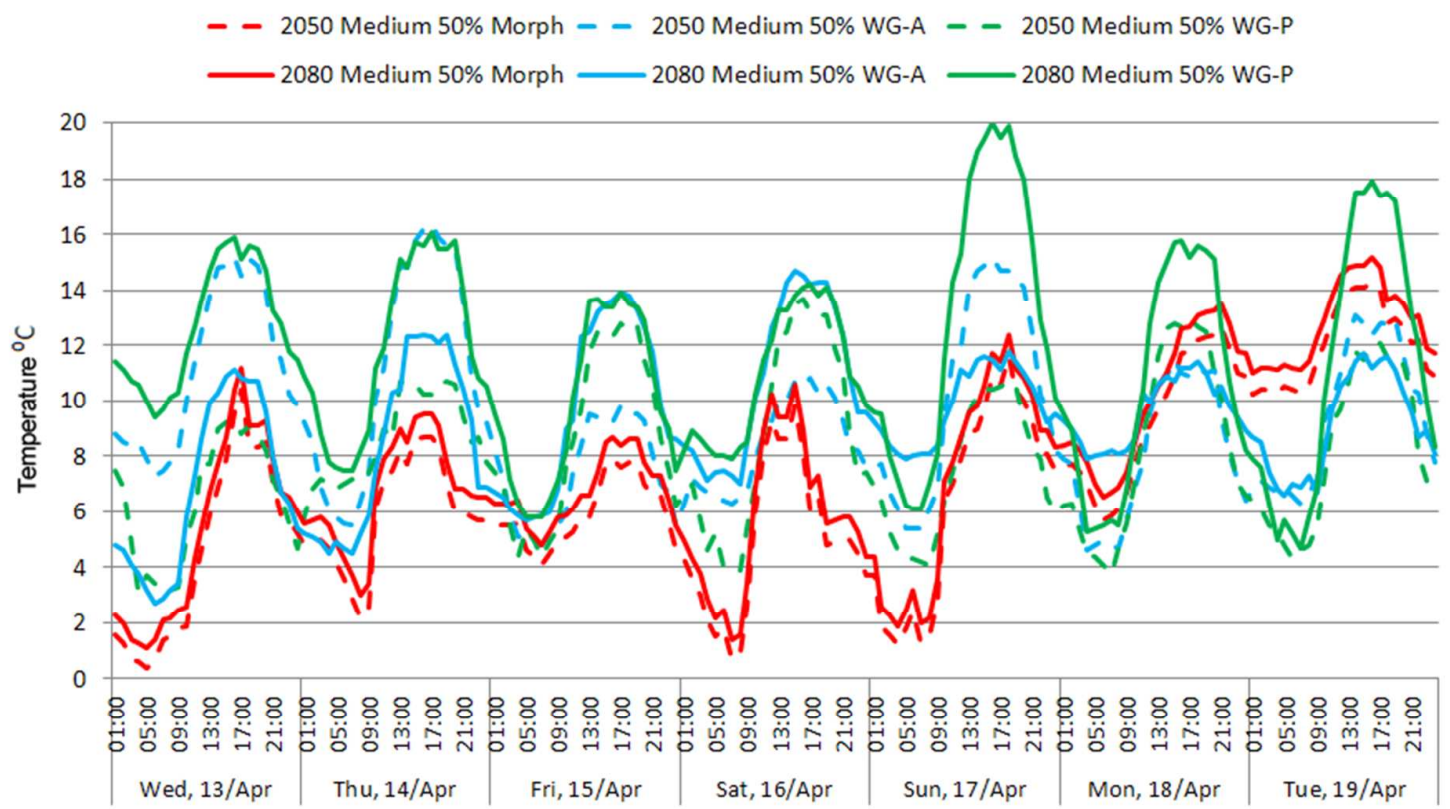

Figure 6 Hourly temperatures 

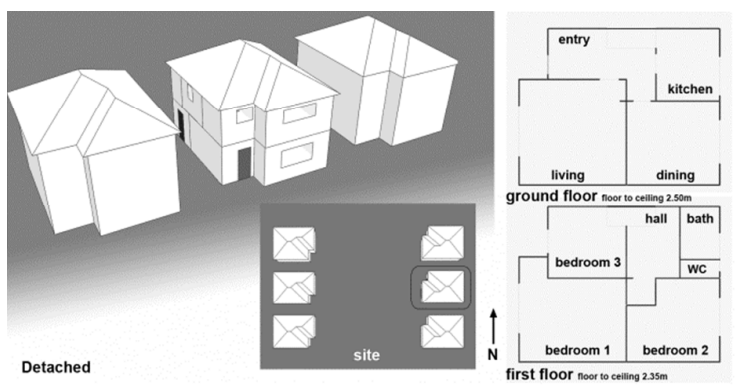

Mid-terrace
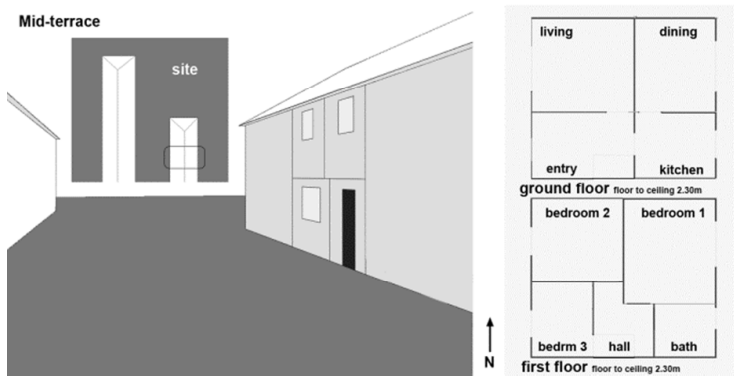
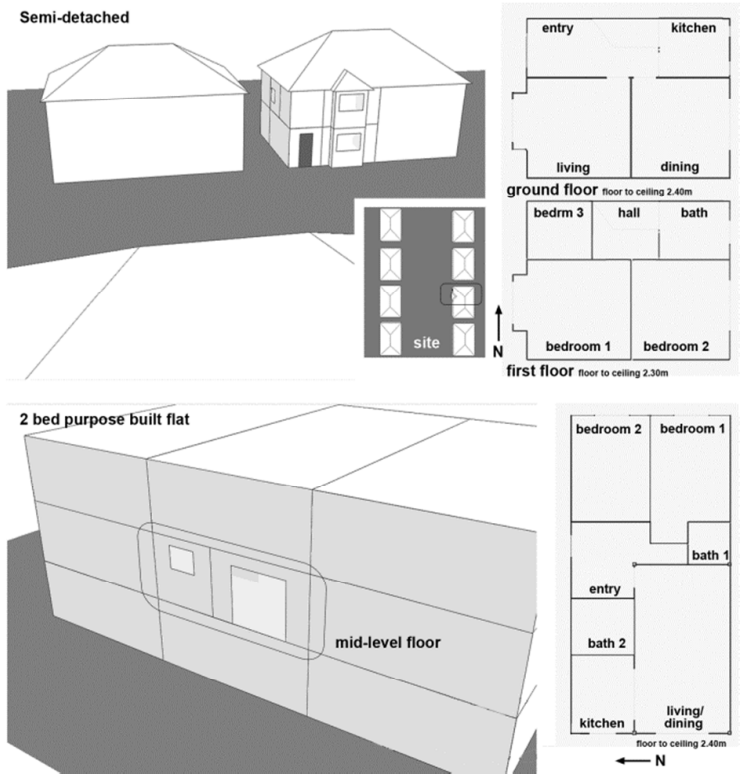

Figure 7 Image of the plans and perspectives showing orientations and room divisions of the four home types 


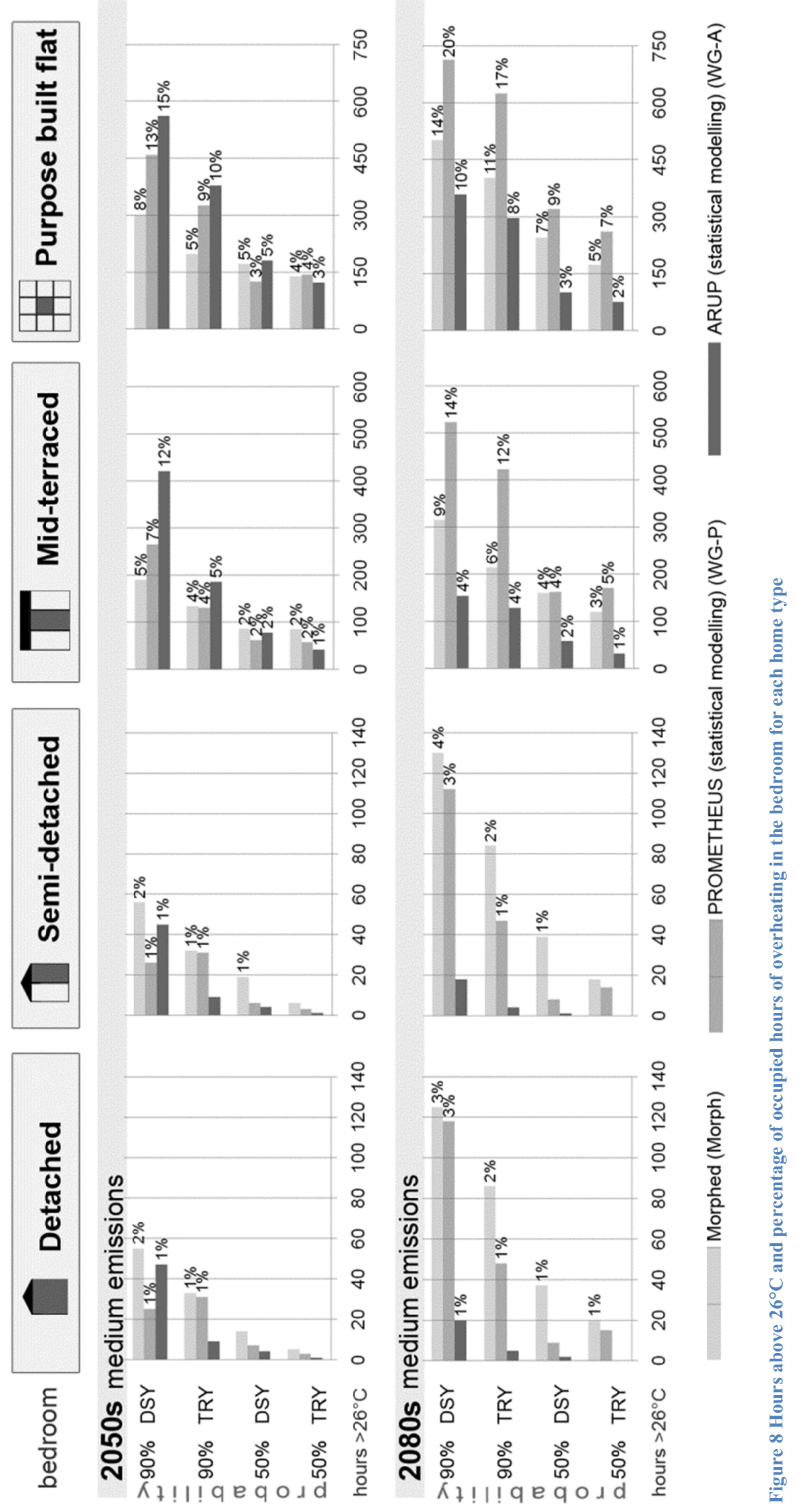




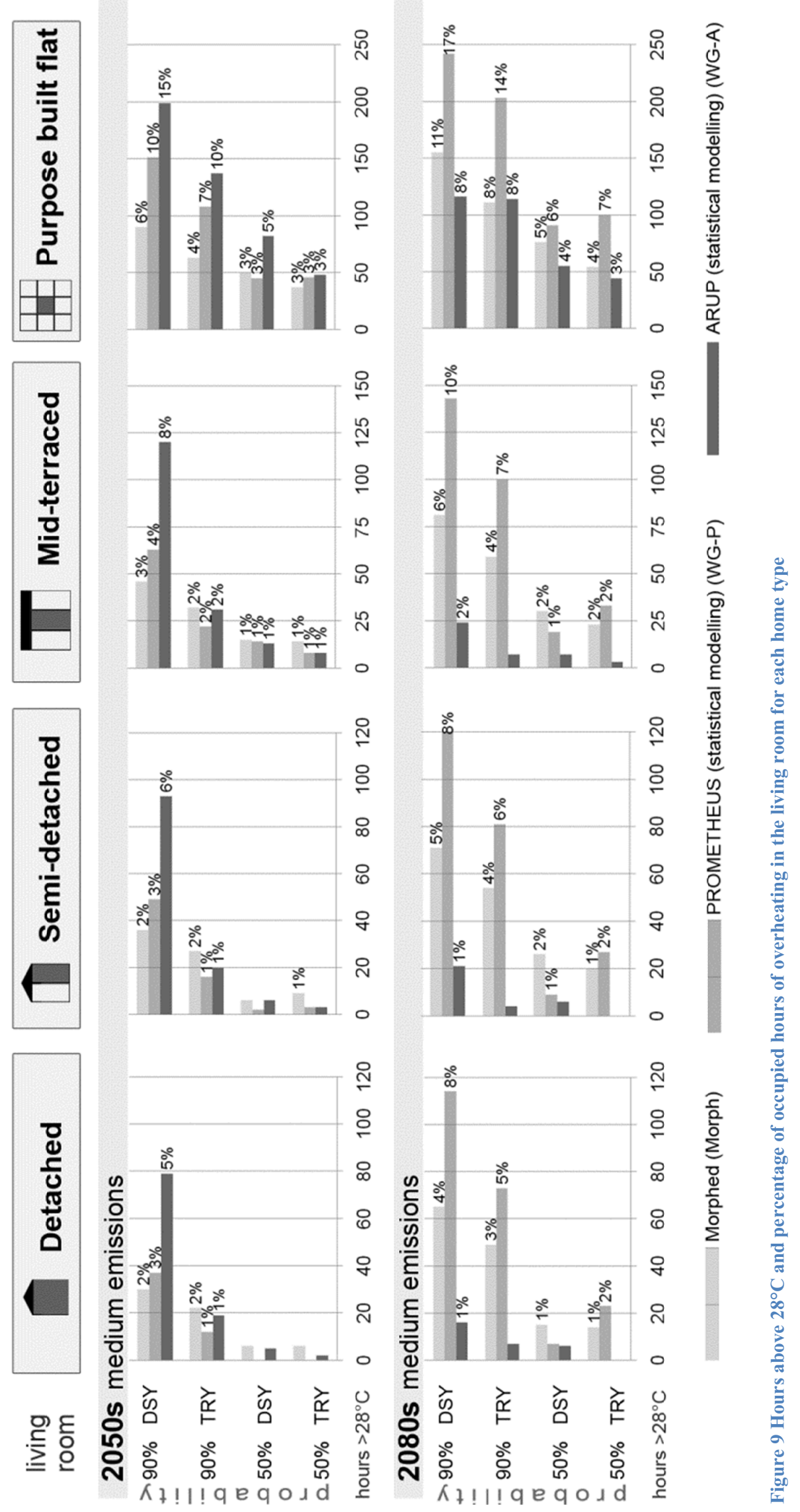




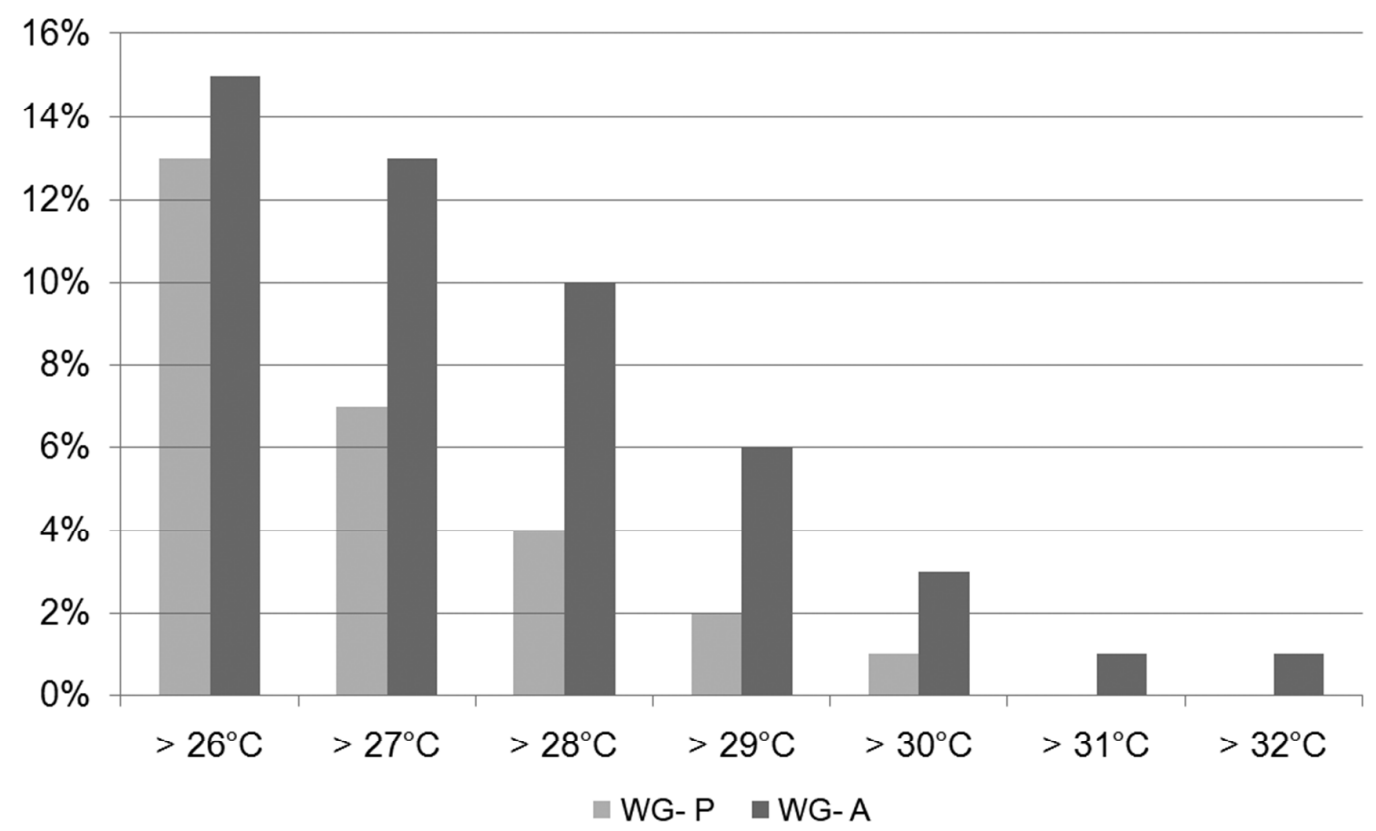

Figure 10 Percentage of overheating hours above a specific temperature for the 2050s, medium emissions scenario at $90 \%$ probability 


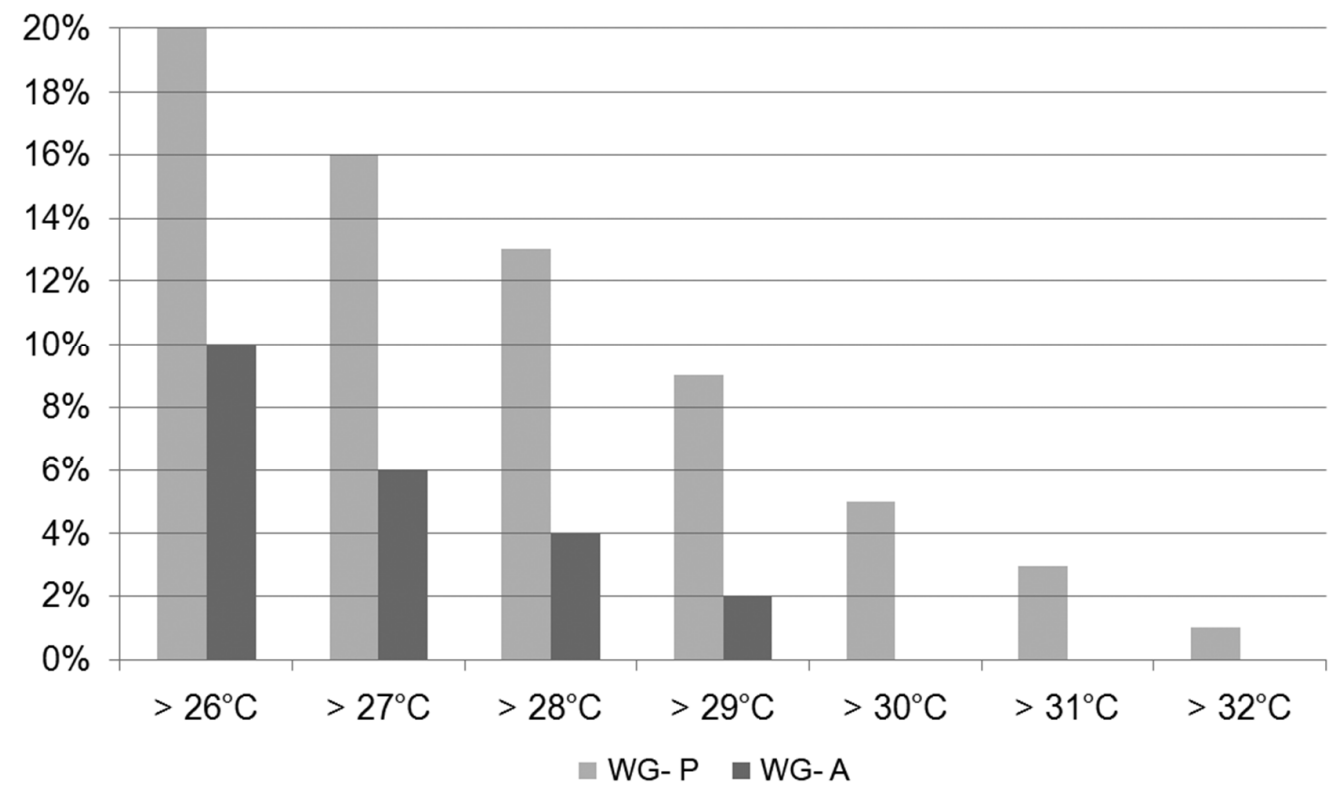

Figure 11 Percentage of overheating hours above a specific temperature for the 2080s, medium emissions scenario at $90 \%$ probability 


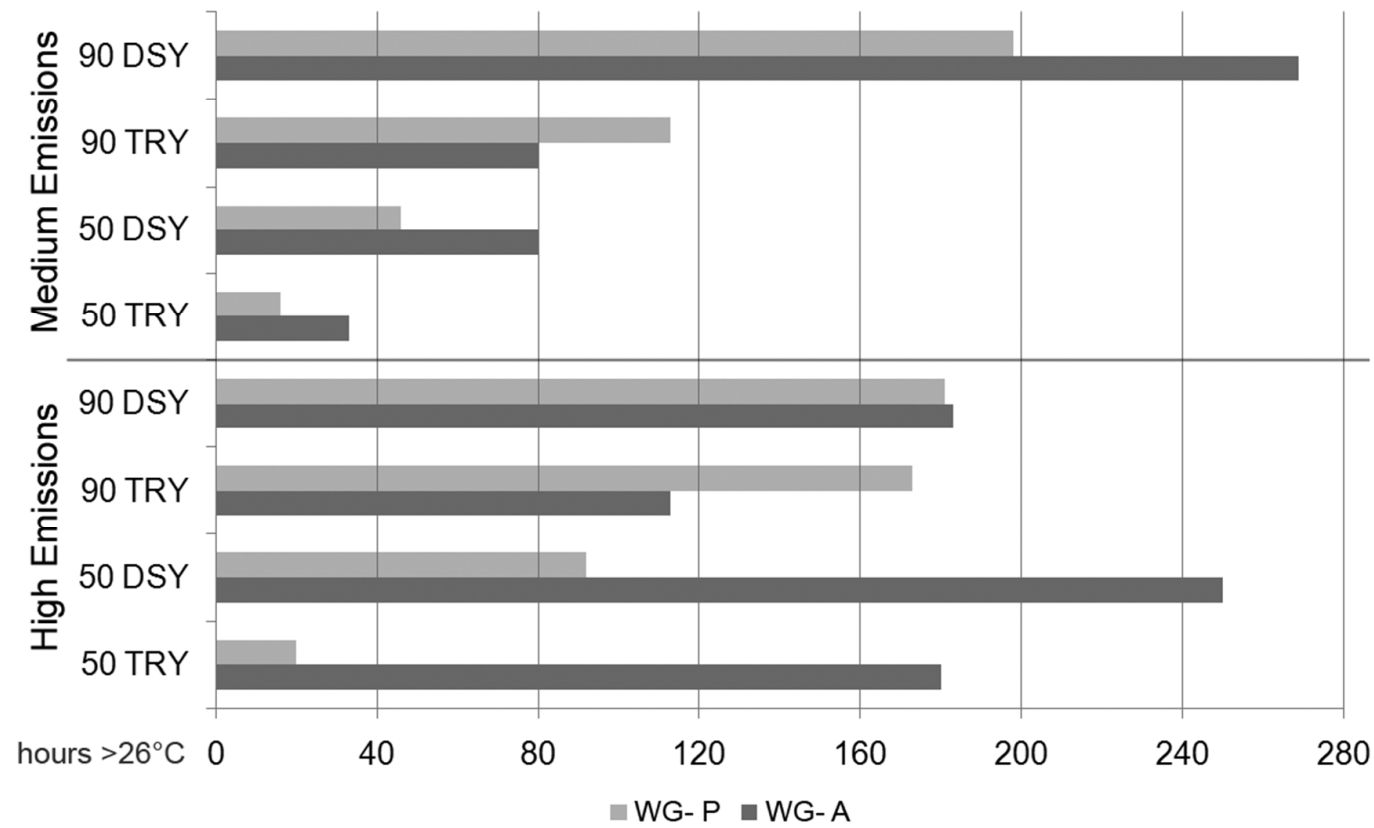

Figure 12 Number of occupied hours above $26^{\circ} \mathrm{C}$ in the primary bedroom of the flat for 2030 s medium and high emissions scenarios 
Typical variable combinations for FWY generation

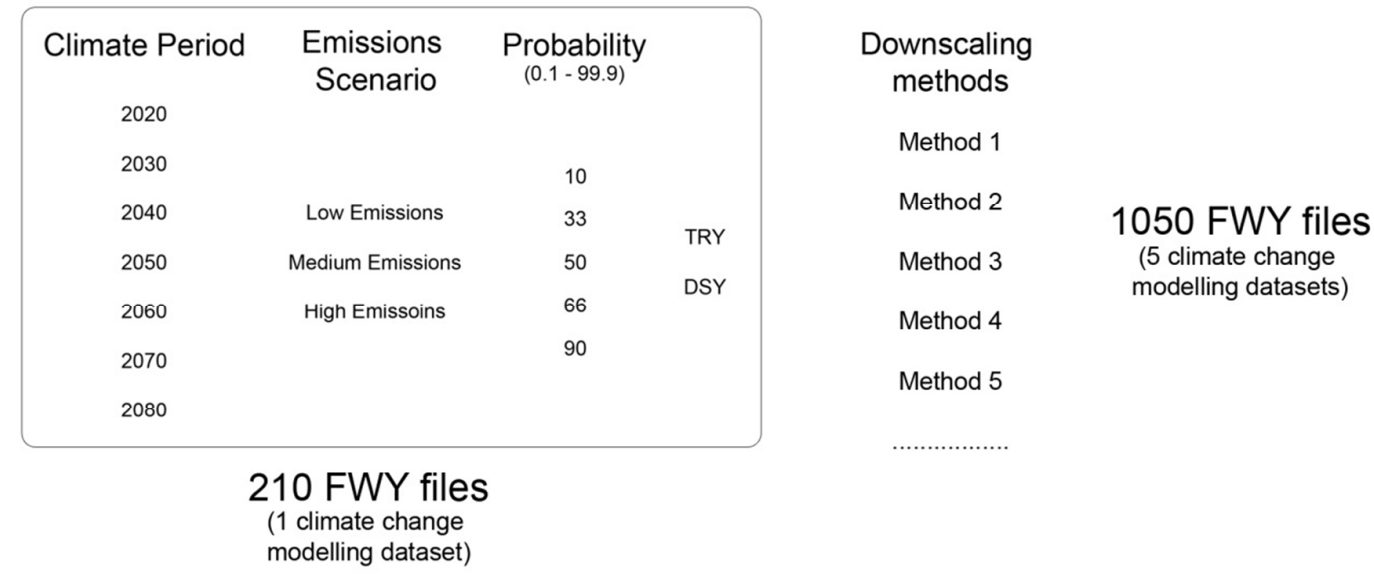

Figure 13 Diagrammatic explanation of FWY datasets. Note: an entire FWY dataset shown (enclosed in the box) is an example of what would be necessary to embody the probabilistic nature of the climate change data and to allow a user access to all climate periods and emissions scenario options. 
Tables

Table 1 Summary of future weather data

\begin{tabular}{|l|l|l|l|l|l|}
\hline \multicolumn{1}{|c|}{ Name of weather data } & $\begin{array}{c}\text { Climate } \\
\text { projection }\end{array}$ & Method & $\begin{array}{c}\text { Sampling } \\
\text { method in } \\
\text { WG }\end{array}$ & \multicolumn{1}{|c|}{$\begin{array}{c}\text { Complete/ } \\
\text { composited year }\end{array}$} & $\begin{array}{c}\text { Short name } \\
\text { in this } \\
\text { paper }\end{array}$ \\
\hline CIBSE Future DSY & UKCIP02 & Morphing & $/$ & Complete & $/$ \\
\hline ARUP morphed DSY & UKCP09 & Morphing & Random & Complete & Morph \\
\hline ARUP WG DSY & UKCP09 & Method F & Random & Complete & WG-A \\
\hline COPSE Manchester DRY & UKCP09 & Method A & Random & Composited & $/$ \\
\hline COPSE Northumbria DRY & UKCP09 & Method B & Random & Composited & $/$ \\
\hline PROMETHEUS DSY & UKCP09 & Method E & Random & Composited & WG-P \\
\hline PROCLIMATION DSY & UKCP09 & Method C & Random & Complete & $/$ \\
\hline PROCLIMATION DSY & UKCP09 & Method D & Random & Complete & $/$ \\
\hline PROCLIMATION DSY & UKCP09 & Method G & Percentile & Complete & $/$ \\
\hline PROCLIMATION DSY & UKCP09 & Method H & Percentile & Complete & $/$ \\
\hline
\end{tabular}

Table 2 Weather files used for comparison

\begin{tabular}{|c|c|c|}
\hline \multirow{2}{*}{ UKCP09 Projection } & Source / title & Weather file type \\
\hline \multirow{3}{*}{2050 Medium 50\% } & Morph & DSY \\
\cline { 2 - 3 } & WG-A & DSY \\
\cline { 2 - 3 } 2050 Medium 90\% & WG-P & DSY \\
\cline { 2 - 3 } & Morph & DSY \\
\cline { 2 - 3 } & WG-A & DSY \\
\hline \multirow{3}{*}{2080 Medium 50\% } & Morph & DSY \\
\cline { 2 - 3 } & WG-A & DSY \\
\cline { 2 - 3 } & WG-P & DSY \\
\hline \multirow{3}{*}{2080 Medium 90\% } & Morph & DSY \\
\cline { 2 - 3 } & WG-A & DSY \\
\cline { 2 - 3 } & WG-P & DSY \\
\hline
\end{tabular}


Table 3 Climate change projections for the case study location, Stockport, 25km grid cell 1274(UK Climate Projections 2011)

\begin{tabular}{lc|cc|c}
\hline Climate change variable & \multicolumn{2}{c}{$\mathbf{2 0 5 0}$ medium emissions } & \multicolumn{2}{c}{$\mathbf{2 0 8 0}$ medium emissions } \\
& $\mathbf{5 0 \%}$ & $\mathbf{9 0 \%}$ & $\mathbf{5 0 \%}$ & $\mathbf{9 0 \%}$ \\
Summer temperature change & $+2.4^{\circ} \mathrm{C}$ & $+4.0^{\circ} \mathrm{C}$ & $+3.4^{\circ} \mathrm{C}$ & $+5.6^{\circ} \mathrm{C}$ \\
Summer NSSWF change & $+6.4 \mathrm{~W} / \mathrm{m}^{2}$ & $+17.0 \mathrm{~W} / \mathrm{m}^{2}$ & $+8.5 \mathrm{~W} / \mathrm{m}^{2}$ & $+21.6 \mathrm{~W} / \mathrm{m}^{2}$ \\
\hline
\end{tabular}

